\title{
Amyotrophic lateral sclerosis (ALS) among immigrant groups and Swedish-born individuals: a cohort study of all adults 18 years of age and older in Sweden
}

\author{
Per Wändell ${ }^{1}(1) \cdot$ Sten Fredrikson ${ }^{2} \cdot$ Axel C. Carlsson $^{1,3} \cdot{\text { Xinjun } \mathrm{Li}^{4} \cdot \text { Jan Sundquist }}^{4,5,6} \cdot$ Kristina Sundquist $^{4,5,6}$
}

Received: 3 June 2021 / Revised: 17 August 2021 / Accepted: 18 August 2021 / Published online: 24 August 2021

(c) The Author(s) 2021

\begin{abstract}
Background There is a lack of studies of amyotrophic lateral sclerosis (ALS) in immigrants.

Objective The objective is to study the association between country of birth and incident ALS in first-generation immigrants versus Swedish-born individuals, and in second-generation immigrants versus native Swedes.

Methods Study populations included all adults aged 18 years and older in Sweden, in the first-generation study 6,128,698 individuals (2,975,141 men, 3,153,557 women) with 5,344 ALS cases ( $3017 \mathrm{men}, 2327$ women), and in the second-generation study 4,588,845 individuals (2,346,855 men and 2,241,990 women) with 3,420 cases (2027 men and 1393 women). ALS was defined as having at least one registered diagnosis of ALS in the National Patient Register 1998-2017. The incidence of ALS in different first-generation immigrant groups versus Swedish-born individuals was assessed by Cox regression, expressed as hazard ratios (HRs) with 95\% confidence intervals (CI). The models were stratified by sex and adjusted for age, geographical residence in Sweden, educational level, marital status, and neighbourhood socioeconomic status.

Results After adjusting for potential confounders, the HRs were lower in foreign-born men, 0.71 (95\% CI 0.63-0.81), and women, 0.80 (95\% CI 0.70-0.92). The ALS risk was lower among men and women from most Western countries (Europe outside Nordic countries, and North America), and from other regions of the world (Africa, Asia, and Latin America). Among men and women with foreign-born parents, the risk of ALS did not differ significantly from native Swedes.

Significance In general, the risk of ALS was lower in first-generation men and women but did not differ in second-generation individuals.
\end{abstract}

Keywords ALS · Gender · Immigrants · Neighborhood $\cdot$ Socioeconomic status

Per Wändell

per.wandell@ki.se

1 Division of Family Medicine and Primary Care, Department of Neurobiology, Care Sciences and Society, Karolinska Institutet, Alfred Nobels Allé 23, 14183 Huddinge, Sweden

2 Division of Neurology, Department of Clinical Neuroscience, Karolinska Institutet Huddinge, Stockholm, Sweden

3 Academic Primary Health Care Centre, Stockholm Region, Stockholm, Sweden

4 Center for Primary Health Care Research, Lund University, Malmö, Sweden

5 Department of Family Medicine and Community Health, Department of Population Health Science and Policy, Icahn School of Medicine At Mount Sinai, New York, NY, USA

6 Center for Community-Based Healthcare Research and Education (CoHRE), Department of Functional Pathology, School of Medicine, Matsue, Shimane University, Matsue, Japan

\section{Introduction}

Amyotrophic lateral sclerosis (ALS), Lou Gehrig's disease, is a neurodegenerative disease of motor neurons, both in primary motor cortex, cortico-spinal tracts, brainstem and spinal cord [1]. The disease is characterized by a progressive muscular paralysis that does not affect the sensory neurons, the senses or mental functioning [2].

The prevalence of ALS is rather uniform in Western countries, with 5.2 per 100,000 [1]. The mean onset of ALS is estimated at 60 years of age for sporadic cases [1], with a slight male preponderance, $\mathrm{M} / \mathrm{F}$ ratio around 1.5 . The disease leads to death in respiratory failure usually within 2-5 years, earlier in the bulbar onset type (primary bulbar palsy, PBP) and later in the spinal onset type (classical or Charcot's ALS) $[2,3]$. 
The incidence of ALS in the world in recent studies is estimated to between 0.6 and 3.8 per 100,000 personyears [4], with an estimated pooled incidence of 1.7 per 100,000 person-years [5]. However, the incidence differs throughout the world, with a standardized incidence rate in Northern Europe of 1.89 per 100,000 person-years, compared to East Asia with 0.83 per 100,000 person-years, and South Asia with 0.73 per 100,000 person-years [5]. In three European countries, i.e. Italy, Ireland and the UK, the incidence has been estimated between 2.2 per 100,000 [3], but an increasing incidence has been shown with up to 3.8 per 100,000 in Scotland [6]. In Sweden, the incidence is estimated at 3.8 per 100,000 person-years, using data from a population-based motor neuron disease register [7].

These differences by region of origin led us to our aim in the present study, i.e., to estimate the incidence of ALS in first- and second-generation immigrants in Sweden compared to Swedish-born individuals and Swedish-born individuals with Swedish-born parents, respectively.

\section{Methods}

\section{Design}

The nationwide registers used in the present study were the Total Population Register, including data on socioeconomic factors and country of birth, and the National Patient Register (NPR), including diagnoses from hospital care and from 2001 also from out-patient care from hospitals. Subjects aged 18 years of age and older were included in the study. The follow-up period ran from January 1, 1998 until hospitalisation/out-patient diagnosis of ALS at age 18 years or more, death, emigration or the end of the study period on December 31, 2017, whichever came first. Out-patient diagnoses were included nationwide from 2001 and onwards from specialist care but not primary health care. First- and second-generation immigrants were included, divided by region of origin or by region of origin in the parents of the individuals, respectively. This study was approved by the Regional Ethical Review Board in Lund, Sweden (No. 2012/795). Participant consent was not required as this study used only pseudonymized registrybased administrative secondary data.

\section{Outcome variable}

ALS (Amyotrophic Lateral Sclerosis) or Familial Motor Neuron Disease (G12.2).

\section{Co-morbidities}

We also identified co-morbidities according to ICD-10 for the following diagnoses: diabetes (E10-E14), heart diseases (I05-09, I11, I13, I20-25, I30-43, I48, I50, I51-53) and dementia (F00, F01, F02, F03, G30, and G31.8A).

\section{Demographic and socioeconomic variables}

The study population was stratified by sex.

Age was used as a continuous variable in the analysis.

Educational attainment was categorised as $\leq 9$ years (partial or complete compulsory schooling), 10-12 years (partial or complete secondary schooling) and $>12$ years (attendance at college and/or university).

Marital status was categorized as married or not being married.

Geographic region of residence was included in order to adjust for possible regional differences in hospital admissions and was categorised as (1) large cities, (2) southern Sweden and (3) northern Sweden. Large cities were defined as municipalities with a population of $>200,000$ and comprised the three largest cities in Sweden: Stockholm, Gothenburg and Malmö.

Region of origin of first-generation immigrants, or of the parents to second-generation immigrants, were categorized into 1. Nordic countries, 2. Europe (with the exclusion of Nordic countries) and North America, and 3. Asia, Africa and Latin America.

\section{Neighbourhood deprivation}

The neighborhood deprivation index was categorized into four groups: more than one standard deviation (SD) below the mean (low deprivation level or high socio-economic status (SES)), more than one SD above the mean (high deprivation level or low SES), and within one SD of the mean (moderate SES or moderate deprivation level) used as reference group, and also unknown neighborhood SES.

\section{Statistical analysis}

Continuous variables are presented as mean and standard deviations, and categorical variables are presented as counts and percentages. Cox regression analysis was used for estimating the risk (hazard ratios (HR) with 95\% confidence intervals (CI)) of incident ALS in different immigrant groups compared to the Swedish-born population during the follow-up time. For the second-generation immigrants, Swedish-born individuals with Swedish-born parents were used as referents. All analyses were stratified by sex. Three 
models were used in our analyses: Model 1 was adjusted for age and region of residence in Sweden, and Model 2 for age, region of residence in Sweden, educational level, marital status and neighborhood SES, and Model 3 as Model 3 but also for co-morbidities (diabetes, heart diseases and dementia). We also performed an age-stratified analysis in the firstgeneration study, i.e., in the age intervals $18-59$ years of age, and $\geq 60$ years of age.

\section{Results}

In the first-generation study (Table 1, Supplementary Tables $1 \mathrm{a}, \mathrm{b})$, totally $6,128,698$ individuals $(2,975,141$ men and 3,153,557 women) with 5,344 ALS cases (3017 men and 2327 women). For the first-generation study, the age-standardised incidence in the ages 18 years and above was for men and women, respectively, 6.6 and 4.6 per 100,000 patient-years (Supplementary Fig. S1); and for all Swedish-born and foreign-born, respectively, 5.9 and 3.4 per 100,000 patient-years (Supplementary Fig. S2), with the peak incidence rate in the years 75-79 years of age. In the second-generation study (Table 1, Supplementary
Table 1 Characteristics of the study populations in firstgeneration and the secondgeneration studies and the number of cases of ALS in each group

\begin{tabular}{|c|c|c|c|c|c|c|c|c|}
\hline & \multicolumn{4}{|c|}{ First-generation individuals } & \multicolumn{4}{|c|}{ Second-generation individuals } \\
\hline & \multicolumn{2}{|l|}{ Population } & \multicolumn{2}{|l|}{ Cases } & \multicolumn{2}{|l|}{ Population } & \multicolumn{2}{|l|}{ Cases } \\
\hline & No. & $\%$ & No. & $\%$ & No. & $\%$ & No. & $\%$ \\
\hline Total population & $6,128,698$ & & 5344 & & $4,588,845$ & & 3420 & \\
\hline \multicolumn{9}{|l|}{ Gender } \\
\hline Males & $2,975,141$ & 48.5 & 3017 & 56.5 & $2,346,855$ & 51.1 & 2027 & 59.3 \\
\hline Females & $3,153,557$ & 51.5 & 2327 & 43.5 & $2,241,990$ & 48.9 & 1393 & 40.7 \\
\hline \multicolumn{9}{|l|}{ Immigrant status* } \\
\hline Swedish & $5,093,177$ & 83.1 & 4800 & 89.8 & $4,056,228$ & 88.4 & 3163 & 92.5 \\
\hline Foreign born & $1,035,521$ & 16.9 & 544 & 10.2 & 532,617 & 11.6 & 257 & 7.5 \\
\hline \multicolumn{9}{|l|}{ Age (years) } \\
\hline $18-39$ & $2,337,436$ & 38.1 & 362 & 6.8 & $2,278,761$ & 49.7 & 394 & 11.5 \\
\hline $40-49$ & $1,042,606$ & 17.0 & 726 & 13.6 & 989,623 & 21.6 & 746 & 21.8 \\
\hline $50-59$ & $1,067,667$ & 17.4 & 1539 & 28.8 & 957,788 & 20.9 & 1455 & 42.5 \\
\hline $60+$ & $1,680,989$ & 27.4 & 2717 & 50.8 & 362,673 & 7.9 & 825 & 24.1 \\
\hline \multicolumn{9}{|l|}{ Educational level } \\
\hline$\leq 9$ & $2,291,344$ & 37.4 & 2209 & 41.3 & $1,125,014$ & 24.5 & 1100 & 32.2 \\
\hline $10-11$ & $2,070,945$ & 33.8 & 1880 & 35.2 & $2,169,870$ & 47.3 & 1473 & 43.1 \\
\hline$\geq 12$ & $1,766,409$ & 28.8 & 1255 & 23.5 & $1,293,961$ & 28.2 & 847 & 24.8 \\
\hline \multicolumn{9}{|l|}{ Region of residence } \\
\hline Large cities & $2,713,033$ & 44.3 & 2513 & 47.0 & $2,190,792$ & 47.7 & 1605 & 46.9 \\
\hline Southern Sweden & $1,908,984$ & 31.1 & 1734 & 32.4 & $1,570,877$ & 34.2 & 1108 & 32.4 \\
\hline Northern Sweden & $1,506,681$ & 24.6 & 1097 & 20.5 & 827,176 & 18.0 & 707 & 20.7 \\
\hline \multicolumn{9}{|l|}{ Marital status } \\
\hline Married & $3,478,186$ & 56.8 & 3680 & 68.9 & $1,992,644$ & 43.4 & 2123 & 62.1 \\
\hline Not married & $2,650,512$ & 43.2 & 1664 & 31.1 & $2,596,201$ & 56.6 & 1297 & 37.9 \\
\hline \multicolumn{9}{|l|}{ Neighborhood deprivation } \\
\hline Low & 860,478 & 14.0 & 898 & 16.8 & 799,400 & 17.4 & 602 & 17.6 \\
\hline Middle & $2,808,862$ & 45.8 & 2599 & 48.6 & $2,514,367$ & 54.8 & 1854 & 54.2 \\
\hline High & 761,072 & 12.4 & 666 & 12.5 & 609,956 & 13.3 & 431 & 12.6 \\
\hline Unknown & $1,698,286$ & 27.7 & 1181 & 22.1 & 665,122 & 14.5 & 533 & 15.6 \\
\hline Hospital diagnosis of diabetes & 404,462 & 6.6 & 386 & 7.2 & 242,666 & 5.3 & 230 & 6.7 \\
\hline Hospital diagnosis of Heart diseases & $1,080,713$ & 17.6 & 1063 & 19.9 & 481,120 & 10.5 & 512 & 15.0 \\
\hline Hospital diagnosis of dementia & 174,119 & 2.8 & 184 & 3.4 & 35,882 & 0.8 & 112 & 3.3 \\
\hline
\end{tabular}

*Immigration status in the second-generation was defined according to parental birth countries 
Tables 2a, b), 4,588,845 individuals $(2,346,855$ men and 2,241,990 women) with 3,420 cases (2027 men and 1393 women). For the second-generation study, the agestandardised incidence in the ages 18 years and above was for men and women, respectively, 4.7 and 3.3 per 100,000 patient-years (Supplementary Fig. S3); and for native Swedes and individuals with foreign-born parents, respectively, 4.4 and 2.1 per 100,000 patient years (Supplementary Fig. S4), with the peak incidence rate for all men and women and all native Swedes 80 years and above, and for individuals with foreign-born parents in the years 75-79 years of age.

In the first-generation study, among foreign-born men, the risk of ALS was higher for the two lower educational levels (Supplementary Table 3), and among foreign-born women, the risk of ALS was lower in the mid-level of education (Supplementary Table 4). For marital status, the ALS risk was higher among Swedish-born men and women in the first-generation study (Supplementary Tables 3 and 4). For region in Sweden, the risk was lower for Swedish-born men for both Southern and Northern Sweden, and for foreignborn men in Northern Sweden, while in the second-generation study, the risk of ALS was higher for native individuals in Northern Sweden (Supplementary Table 5). For neighborhood deprivation level, among foreign-born man and women the risk was lower among those living in neighbourhoods with high or unknown deprivation level, and for Swedishborn women the risk was borderline lower for those living in middle deprivation level.

As regards co-morbidities, the risk of ALS was lower for Swedish-born men and women for diabetes, heart diseases and dementia, and for foreign-born men and women for heart diseases; in the second-generation study the risk of ALS was lower for native Swedes for diabetes and heart diseases, but higher for dementia.

The male to female ratio was in the first-generation study was 1.37 , and it was 1.39 in the second-generation. As regards age, in the first-generation study the mean and median age, respectively, was for Swedish-born men 67.9 years (sd 11.2) and 69 years, respectively, and for women 69.3 years (sd 11.5) and 70, respectively; and for foreign-born men 64.7 years (sd 11.2) and 66 years, respectively, and for foreign-born women 65.9 years (sd 12.0) and 67 , respectively. In the second-generation study the corresponding mean and median ages were for men with Swedish-born parents 62.4 years (sd 9.9) and 63, and for women with Swedish-born parents 63.3 years (sd 9.9) and 65, and for men with foreign-born parents 56.5 years (sd 11.3) and 56 , and for women with foreign-born parents 57.1 years (sd 10.4 ) and 58 , respectively.

In the first-generation study (Table 2), among foreign-born men, the fully adjusted HR was 0.71 (95\% CI $0.63-0.81$ ), and among foreign-born women, the fully adjusted HR was 0.80 (95\% CI 0.70-0.92). The risk of ALS was lower among men and women from Western countries (Europe outside Nordic countries, and North America), and from other regions of the world (Africa, Asia, and Latin America). In the age-stratified analysis the results were rather similar to those in the main analysis (Table 3).

In the second-generation study (Table 4), among men with foreign-born parents the fully adjusted HR was 1.10 (95\% CI 0.93-1.31), and among women with foreign-born

Table 2 The relative risk of ALS in the first-generation immigrants expressed as hazard ratios (HR) with 95\% confidence intervals (95\% CI)

\begin{tabular}{|c|c|c|c|c|c|c|c|c|c|c|}
\hline & \multirow[t]{2}{*}{$(n)$} & \multicolumn{3}{|c|}{ Model 1} & \multicolumn{3}{|c|}{ Model 2} & \multicolumn{3}{|c|}{ Model 3} \\
\hline & & HR & \multicolumn{2}{|c|}{$95 \% \mathrm{CI}$} & HR & \multicolumn{2}{|c|}{$95 \% \mathrm{CI}$} & HR & \multicolumn{2}{|c|}{$95 \% \mathrm{CI}$} \\
\hline \multicolumn{11}{|l|}{ Men } \\
\hline Sweden & 2716 & 1 & & & 1 & & & 1 & & \\
\hline All foreign-born & 301 & 0.95 & 0.95 & 0.95 & 0.73 & 0.64 & 0.82 & 0.71 & 0.63 & 0.81 \\
\hline Nordic countries & 142 & 0.80 & 0.68 & 0.95 & 0.88 & 0.74 & 1.05 & 0.86 & 0.72 & 1.03 \\
\hline Western countries (rest of Europe, North America) & 95 & 0.60 & 0.49 & 0.73 & 0.62 & 0.50 & 0.76 & 0.61 & 0.49 & 0.74 \\
\hline Others (Africa, Asia, and Latin America) & 64 & 0.60 & 0.47 & 0.77 & 0.64 & 0.49 & 0.82 & 0.65 & 0.50 & 0.83 \\
\hline \multicolumn{11}{|l|}{ Women } \\
\hline Sweden & 2084 & 1 & & & 1 & & & 1 & & \\
\hline All foreign-born & 243 & 0.96 & 0.95 & 0.96 & 0.81 & 0.70 & 0.93 & $\mathbf{0 . 8 0}$ & 0.70 & 0.92 \\
\hline Nordic countries & 158 & 1.07 & 0.91 & 1.26 & 1.07 & 0.91 & 1.26 & 1.06 & 0.89 & 1.25 \\
\hline Western countries (rest of Europe, North America) & 61 & 0.64 & $\mathbf{0 . 5 0}$ & 0.83 & 0.63 & 0.49 & 0.82 & 0.62 & 0.48 & 0.81 \\
\hline Others (Africa, Asia, and Latin America) & 24 & 0.41 & 0.27 & 0.61 & 0.40 & 0.27 & 0.61 & 0.42 & 0.28 & 0.63 \\
\hline
\end{tabular}

Model 1: adjusted for age and region of residence in Sweden; model 2: adjusted for age, region of residence in Sweden, educational level, marital status, and neighborhood deprivations; model 3: model 2+ comorbidities

(n) Observed numbers, $H R$ hazard ratio, $C I$ confidence interval

Bold values are statistically significant 
Table 3 The age-stratified relative risk of ALS in first-generation immigrants expressed as hazard ratios (HR) with $95 \%$ confidence intervals $(95 \% \mathrm{CI})$

\begin{tabular}{|c|c|c|c|c|c|c|c|c|}
\hline & \multicolumn{4}{|c|}{ Aged $18-59$ years } & \multicolumn{4}{|c|}{ Aged $60+$ years } \\
\hline & $(n)$ & $\mathrm{HR}^{*}$ & \multicolumn{2}{|c|}{$95 \% \mathrm{CI}$} & $(n)$ & $\mathrm{HR}^{*}$ & \multicolumn{2}{|c|}{$95 \% \mathrm{CI}$} \\
\hline \multicolumn{9}{|l|}{ Men } \\
\hline Sweden & 1352 & 1 & & & 1363 & 1 & & \\
\hline All foreign-born & 176 & 0.72 & 0.61 & 0.85 & 125 & 0.64 & 0.53 & 0.77 \\
\hline Nordic countries & 73 & 0.80 & 0.63 & 1.02 & 69 & 0.73 & 0.57 & 0.94 \\
\hline $\begin{array}{l}\text { Western Countries } \\
\text { (including North } \\
\text { America) }\end{array}$ & 48 & 0.57 & 0.43 & 0.76 & 47 & 0.57 & 0.43 & 0.77 \\
\hline Others & 55 & 0.81 & 0.62 & 1.07 & 9 & 0.47 & 0.25 & 0.92 \\
\hline \multicolumn{9}{|l|}{ Women } \\
\hline Sweden & 961 & 1 & & & 1122 & 1 & & \\
\hline All foreign-born & 137 & 0.87 & 0.72 & 1.05 & 106 & 0.72 & 0.59 & 0.89 \\
\hline Nordic countries & 82 & 1.07 & 0.85 & 1.36 & 76 & 0.87 & 0.69 & 1.10 \\
\hline $\begin{array}{l}\text { Western Countries } \\
\text { (including North } \\
\text { America) }\end{array}$ & 34 & 0.71 & 0.50 & 1.01 & 27 & 0.52 & 0.36 & 0.77 \\
\hline Others & 21 & 0.62 & 0.40 & 0.96 & 3 & 0.38 & 0.12 & 1.19 \\
\hline
\end{tabular}

(n) Observed numbers, $H R$ hazard ratio, $C I$ confidence interval

*Full adjusted

Bold values are statistically significant

Table 4 The relative risk of ALS in the second-generation immigrants expressed as hazard ratios (HR) with 95\% confidence intervals (95\% CI)

\begin{tabular}{|c|c|c|c|c|c|c|c|c|c|c|}
\hline & \multirow[t]{2}{*}{$(n)$} & \multicolumn{3}{|c|}{ Model 1} & \multicolumn{3}{|c|}{ Model 2} & \multicolumn{3}{|c|}{ Model 3} \\
\hline & & HR & \multicolumn{2}{|c|}{$95 \%$ CI } & HR & \multicolumn{2}{|c|}{$95 \%$ CI } & HR & \multicolumn{2}{|c|}{$95 \%$ CI } \\
\hline Sweden & 1877 & 1 & & & 1 & & & 1 & & \\
\hline All with foreign-born parents & 149 & 1.11 & 0.94 & 1.31 & 1.10 & 0.93 & 1.30 & 1.10 & 0.93 & 1.31 \\
\hline Nordic countries & 93 & 1.15 & 0.93 & 1.42 & 1.13 & 0.92 & 1.40 & 1.14 & 0.92 & 1.40 \\
\hline Western Countries (rest of Europe, North America) & 48 & 1.05 & 0.78 & 1.39 & 1.04 & 0.78 & 1.39 & 1.04 & 0.78 & 1.39 \\
\hline Others (Africa, Asia, and Latin America) & 8 & 1.09 & 0.57 & 2.10 & 1.08 & 0.56 & 2.09 & 1.10 & 0.57 & 2.12 \\
\hline \multicolumn{11}{|l|}{ Women } \\
\hline Sweden & 1286 & 1 & & & 1 & & & 1 & & \\
\hline All with foreign-born parents & 106 & 1.19 & 0.97 & 1.45 & 1.17 & 0.96 & 1.43 & 1.17 & 0.96 & 1.43 \\
\hline Nordic countries & 71 & 1.30 & 1.02 & 1.66 & 1.27 & 1.00 & 1.62 & 1.28 & 1.00 & 1.63 \\
\hline Western Countries (rest of Europe, North America) & 34 & 1.13 & 0.80 & 1.59 & 1.12 & 0.79 & 1.58 & 1.12 & 0.80 & 1.58 \\
\hline Others (Africa, Asia, and Latin America) & 1 & 0.38 & 0.09 & 1.51 & 0.36 & 0.09 & 1.44 & 0.36 & 0.09 & 1.46 \\
\hline
\end{tabular}

Model 1: adjusted for age and region of residence in Sweden; model 2: adjusted for age, region of residence in Sweden, educational level, marital status, and neighborhood deprivations; model 3: model 2+ comorbidities

(n) Observed numbers, $H R$ hazard ratio, CI confidence interval

Bold values are statistically significant

parents the fully adjusted HR was 1.17 (95\% CI 0.96-1.43). The risk of ALS was borderline significant among women with parents from the Nordic countries.

\section{Discussion}

The main findings of this study were significantly lower risks of ALS among foreign-born men and women, but not among men and women born in Sweden with foreign-born parents. Among foreign-born men and women, the risk 
of ALS was lower among men and women from Europe outside Nordic countries, and from Asia, Africa or Latin America, while a borderline significantly higher risk was found among women with parents from the Nordic countries.

We choose to categorize first- and second-generation immigrants into groups. We could expect a similar risk in Western first-generation immigrants but found this only for men and women from the Nordic countries, while the risk was lower in men and women from the rest of Europe and North America. The "healthy migrant effect" is often mentioned as an explanation to a lower morbidity among foreign-born [8], and sometimes also the "salmon bias" or "re-migration bias" [9], i.e. that migrants tend to go back to their country of origin when expecting to die and possibly in this case when they contract symptoms of ALS. However, Danish studies found the "healthy migrant effect" questionable [10], and furthermore found no evidence for the "salmon bias" hypothesis to be true [11].

Regarding the third group, i.e. individuals from Asia, Africa or Latin America, there are previous studies showing a lower risk of ALS, especially among Asian populations $[12,13]$, i.e. in line with our findings. However, studies from Africa and Latin America are scarce, but with a low prevalence.

Another possible explanation to the lower risk of ALS in the first generation of immigrants could a lower detection rate, which then could be explained by a lower mental health, language and cultural differences making the detection of ALS lower. However, with a serious and life-threatening disease like ALS this seems less likely.

Regarding the incidence rate, we chose to include men and women 18 years of age and above. If adjusting to the whole population the estimated incidence rate for all ages would be 4.4 per 100,000 person-years, i.e. slightly higher than the earlier reported value of 3.8 per 100,000 personyears [7]. As regards sex distribution, we found a male to female ratio of around 1.4 in both the first- and secondgeneration study, i.e. close to what is found earlier [1]. The mean and median ages were around 60 years of age, i.e. what is described earlier for sporadic cases [1], although the peak incidence rate was rather high, i.e. in the agegroup 75-79 years. In the first-generation study, the mean and median ages were higher than in the second-generation study, reflecting the differences in age distribution in the studied populations, although the peak incidence agegroups were similar. Besides, the mean and median ages were higher in Swedish-born men and women, as well as in men and women with Swedish-born parents, compared to the second-generation men and women, also reflecting differences in age distribution.

This study has limitations. We used the Swedish NPR, in contrast to an earlier study using data from the population-based motor neuron disease register [7]. The number of cases was quite low, why we had to categorize the individuals into a few groups, i.e., Nordic countries; Europe (except Nordic countries) and North America; and Asia, Africa and Latin America. Despite this, the number of cases were low, especially in the second-generation study among those with parents from Asia, Africa and Latin America, why these results should be interpreted with great caution. Furthermore, we did not have access to genetic data or familiarity of ALS, which would be of interest considering the differences in ALS incidence and prevalence in the world but also between different European regions which could be related to genetic differences $[2,3,14]$. The strengths lie in the Swedish registers that have been shown to be of high quality $[15,16]$, and we expect that we have detected most cases in the Swedish National Patient Register.

In conclusion, we found a lower ALS risk among foreignborn men and women, with lower risks for two of the groups, i.e. men and women from Europe outside the Nordic countries, and from Asia, Africa and Latin America. The lower risk among non-Western immigrants is expected, while we have no good explanation for Western immigrants. For men and women born in Sweden with foreign-born parents the risks were similar compared to native Swedes.

Supplementary Information The online version contains supplementary material available at https://doi.org/10.1007/s00415-021-10765-6.

Funding Open access funding provided by Karolinska Institute. This work was supported by ALF funding awarded to Kristina Sundquist and by grants from the Swedish Research Council (awarded to Kristina Sundquist and to Jan Sundquist).

Availability of data and materials The authors are not allowed to share the used data from the data sources being used.

\section{Declarations}

Conflicts of interest The authors have no conflict of interest to report.

Ethical approval All procedures performed in studies involving human participants were in accordance with the ethical standards of the institutional and/or national research committee and with the 1964 Helsinki Declaration and its later amendments or comparable ethical standards.

The study was approved by the Regional Ethical Review Board in Lund (Ref. No. 2012/795).

Informed consent Informed consent was not applicable, as the study was based on anonymized data from registers. Research data are not shared.

Open Access This article is licensed under a Creative Commons Attribution 4.0 International License, which permits use, sharing, adaptation, distribution and reproduction in any medium or format, as long as you give appropriate credit to the original author(s) and the source, provide a link to the Creative Commons licence, and indicate if changes were made. The images or other third party material in this article are 
included in the article's Creative Commons licence, unless indicated otherwise in a credit line to the material. If material is not included in the article's Creative Commons licence and your intended use is not permitted by statutory regulation or exceeds the permitted use, you will need to obtain permission directly from the copyright holder. To view a copy of this licence, visit http://creativecommons.org/licenses/by/4.0/.

\section{References}

1. Wijesekera LC, Leigh PN (2009) Amyotrophic lateral sclerosis. Orphanet J Rare Dis 4:3

2. Chio A, Logroscino G, Traynor BJ, Collins J, Simeone JC, Goldstein LA, White LA (2013) Global epidemiology of amyotrophic lateral sclerosis: a systematic review of the published literature. Neuroepidemiology 41:118-130

3. Logroscino G, Traynor BJ, Hardiman O, Chio A, Mitchell D, Swingler RJ, Millul A, Benn E, Beghi E (2010) Incidence of amyotrophic lateral sclerosis in Europe. J Neurol Neurosurg Psychiatry 81:385-390

4. Longinetti E, Fang F (2019) Epidemiology of amyotrophic lateral sclerosis: an update of recent literature. Curr Opin Neurol 32:771-776

5. Marin B, Boumediene F, Logroscino G, Couratier P, Babron MC, Leutenegger AL, Copetti M, Preux PM, Beghi E (2017) Variation in worldwide incidence of amyotrophic lateral sclerosis: a metaanalysis. Int J Epidemiol 46:57-74

6. Leighton DJ, Newton J, Stephenson LJ, Colville S, Davenport R, Gorrie G, Morrison I, Swingler R, Chandran S, Pal S, Consortium C-M (2019) Changing epidemiology of motor neurone disease in Scotland. J Neurol 266:817-825

7. Longinetti E, Regodon Wallin A, Samuelsson K, Press R, Zachau A, Ronnevi LO, Kierkegaard M, Andersen PM, Hillert J, Fang F, Ingre C (2018) The Swedish motor neuron disease quality registry. Amyotroph Lateral Scler Frontotemporal Degener 19:528-537
8. Kennedy S, Kidd MP, McDonald JT, Biddle N (2015) The healthy immigrant effect: patterns and evidence from four countries. Int Migrat Integrat 16:317-332

9. Abraido-Lanza AF, Dohrenwend BP, Ng-Mak DS, Turner JB (1999) The Latino mortality paradox: a test of the "salmon bias" and healthy migrant hypotheses. Am J Public Health 89:1543-1548

10. Norredam M, Agyemang C, Hoejbjerg Hansen OK, Petersen JH, Byberg S, Krasnik A, Kunst AE (2014) Duration of residence and disease occurrence among refugees and family reunited immigrants: test of the "healthy migrant effect" hypothesis. Trop Med Int Health 19:958-967

11. Norredam M, Hansen OH, Petersen JH, Kunst AE, Kristiansen M, Krasnik A, Agyemang C (2015) Remigration of migrants with severe disease: myth or reality? - a register-based cohort study. Eur J Public Health 25:84-89

12. Jun KY, Park J, Oh KW, Kim EM, Bae JS, Kim I, Kim SH (2019) Epidemiology of ALS in Korea using nationwide big data. J Neurol Neurosurg Psychiatry 90:395-403

13. Zhou S, Zhou Y, Qian S, Chang W, Wang L, Fan D (2018) Amyotrophic lateral sclerosis in Beijing: epidemiologic features and prognosis from 2010 to 2015. Brain Behav 8:1131

14. Hardiman O, Al-Chalabi A, Brayne C, Beghi E, van den Berg LH, Chio A, Martin S, Logroscino G, Rooney J (2017) The changing picture of amyotrophic lateral sclerosis: lessons from European registers. J Neurol Neurosurg Psychiatry 88:557-563

15. Ludvigsson JF, Almqvist C, Bonamy AK, Ljung R, Michaelsson K, Neovius M, Stephansson O, Ye W (2016) Registers of the Swedish total population and their use in medical research. Eur J Epidemiol 31:125-136

16. Ludvigsson JF, Andersson E, Ekbom A, Feychting M, Kim JL, Reuterwall C, Heurgren M, Olausson PO (2011) External review and validation of the Swedish national inpatient register. BMC Public Health 11:450 